\title{
HISTORIOGRAFIA EDUCACIONAL DA AMAZÔNIA: UMA INTRODUÇÃO
}

\author{
Anselmo Alencar Colares (UFOPA) \\ anselmo.colares@ hotmail.com
}

\section{RESUMO}

Compreender a educação escolar na perspectiva histórica implica em se fazer uma leitura sistemática da produção historiográfica dedicada a esta temática. E quando se trata da Amazônia Colonial, nos vemos diante de um desafio maior, considerando as especificidades presentes naquele período. Este artigo traz um conjunto de autores e obras que são referência para os estudos históricos educacionais e outros menos conhecidos masque são significativos para o entendimento da correlação entre colonização e educação na Amazônia colonial. Palavras-chave: Educação. Amazônia. Historiografia educacional.

\section{AMAZONIAN EDUCATIONAL HISTORIOGRAPHY: AN INTRODUCTION}

\begin{abstract}
Understanding schooling from a historical perspective involves making a systematic reading of the historiographical production dedicated to this issue. And when it comes to the colonial Amazon, we find ourselves faced with a major challenge, considering the specific features of that period. This paper presents a group of authors and works that are references to historical educational studies, and others less known, but which are significant for understanding the correlation between colonization and education in the colonial Amazon.
\end{abstract}

Keywords: Education. Amazon. Educational historiography.

\section{Considerações iniciais: situando o leitor}

Este texto objetiva oferecer uma contribuição para os estudos introdutórios da disciplinaHistória Geral da Educação e História da Educação Brasileira e da Amazônia(a ementa contempla: História da educação face ao processo de formação econômica e social do Brasil e da Amazônia. Educação brasileira e amazônica nos seus aspectos político, econômico e social com ênfase às questões relativas à história da educação na Amazônia). O termo história será utilizado neste texto nos seus dois sentidos: como processo histórico objetivo - os acontecimentos históricos, as coisas feitas pelos homens (res gestae) - e como processo subjetivo - a narração dos acontecimentos, das coisas feitas pelos homens (res gestarum).

A temática regional conquistou espaço privilegiado nas discussões educacionais, mas ainda carece de pesquisas que ofereçam subsídios aos professores e alunos de forma a ir além das curiosidades e das singularidades como se estas não estejam associadas ao movimento geral da história. Os docentes que trabalham com esta disciplina geralmente se veem diante do seguinte impasse: simplesmente inferir que as análises já realizadas por pesquisadores da história da educação brasileira com relação a outras regiões também se aplicam aAmazônia, ou buscar produzir novos conhecimentos pelo caminho da pesquisa.

Revista HISTEDBR On-line, Campinas, n.48, p.13-24 Dez.2012 - ISSN: 1676-2584 
Optei pela segunda alternativa. Por conseguinte, busquei reunir e analisar as fontes disponíveis à luz de um referencial teórico que auxiliasse no desvelamento do que se encontra por trás das simples aparências.

O exercício da docência e, principalmente, os estudos na pós-graduação fizeram-me perceber as lacunas e tenho buscado superá-las. Uma dessas lacunas diz respeito a uma revisão bibliográfica sobre as obras de referência que tratam da história da educação brasileira, buscando nestas obras verificar como os autores analisam as conexões da colonização com as transformações econômicas, religiosas, políticas, sociais, culturais e ideológicas que estavam em curso no "velho" mundo e que engendraram os acontecimentos na região que hoje denominamos Amazônia.

Estudar um período em que não há fontes vivas para confirmar ou refutar aquilo que ficou registrado exige do pesquisador que, de alguma maneira, faça uma viagem no tempo e penetre no mundo daquela época, para que se acerque dos embates, do posicionamento dos indivíduos e dos grupos sociais, a fim de que possa com maior segurança reconstruir a trama de relações que deram corpo aos acontecimentos. Espero assim possibilitar a outros que também tomem parte deste desafio.

\section{Catequese e educação no Grão Pará}

Procurei entender a catequese e a educação na complexidade da organização social do Grão-Pará colonial, considerando as interfaces com o processo mais amplo de transformações, o de desenvolvimento do capitalismo. Como nos ensina Prado Jr. (2000, p.19-20),

[...] No seu conjunto, e vista no plano mundial e internacional, a colonização dos trópicos toma o aspecto de uma vasta empresa comercial, mais completa que a antiga feitoria, mas sempre com o mesmo caráter que ela, destinada a explorar os recursos naturais de um território virgem em proveito do comércio europeu. É este o verdadeiro sentido da colonização tropical, de que o Brasil é uma das resultantes; e ele explicará os elementos fundamentais, tanto no econômico como no social, da formação e evolução históricas dos trópicos americanos.

Evidentemente nem todos os que escreveram a nossa história apontam e muito menos ainda explicam esse entrelaçamento. Alguns se limitaram a relatos, registros. Mesmo assim, constituem importantes fontes de pesquisa. Antonio Vieira (1608-1697), João Felipe Bettendorf (1625-1698) e Antônio Ladislau Monteiro Baena (1782-1850), entre outros, nos transmitiram informações indispensáveis para o acompanhamento cronológico da história daquela região, inclusive pelo fato de terem sido testemunhas oculares dos acontecimentos descritos.

Antônio Baena foi autor de monumental obra que abrange o período de 1615 a 1823 , contudo, ele próprio reconheceu os limites teóricos e metodológicos de sua produção:

[...] Todos os meus apontamentos por mim conservados estavaõ no risco de sofrerem descaminho: para evitar este sucedimento dei-me ao penoso trabalho de reuni-los em um volume copiando-os indiscriminadamente; isto he, sem alguma ligaçaõsystematica [...]

Revista HISTEDBR On-line, Campinas, n.48, p.13-24 Dez.2012 - ISSN: 1676-2584 
[...] Dei-lhe o titulo de Compendio das Eras da Província do Pará porque naõ tinha achado abastança de documentos defraudados de alguns papeis por clandestina curiosidade: e sobretudo porque eu me apercebia que naõ girava na órbita de um Joaõ de Barros e de um Eduardo Gibbon para ser Historiador como ellestaõ recomendáveis pela elegante e nítida forma, que deraõaõs seus escriptos, pelo rastreamento exacto, pelas reflexões, e pelos delicados alcances esparsos no tecido dos acontecimentos. (BAENA, 1969, p. 15-16).

Além de Baena, outros autores se dedicaram a tarefa de mostrar como se deu o desenvolvimento histórico do Grão-Pará como, por exemplo, Ernesto Cruz, Vicente Salles e Arthur Cezar Ferreira Reis. Mas ainda é reduzido o número de publicações destinadas à história do Grão-Pará colonial, mesmo se consideradas as mais recentes.

\section{Historiografia da educação no Brasil Colônia: a presença da Amazônia}

Quanto à história da educação no Brasil colonial, pode-se afirmar que se trata de um período que continua a merecer estudos mais aprofundados. Ao realizar a "revisão bibliográfica", tive a oportunidade não só de reler algumas obras, como também de ler outras pela primeira vez, conforme a elas era "apresentado" pelos autores dos chamados compêndios ou manuais ${ }^{1}$ mais difundidos na área.

Livros de caráter mais geral tratam da educação no Brasil de forma bastante sintética e praticamente não fazem referência a regiões específicas, como o Grão-Pará. Vejamos dois exemplos ilustrativos: História geral da pedagogia (título original: Historia general de la pedagogia), e História da educação. Este último dedica 18 das 304 páginas para tratar dos "quadros da história do processo educativo no Brasil"; destas, apenas 3 para falar do período colonial, no qual destaca a Companhia de Jesus e considera que seus colégios eram destinados à formação de uma elite letrada, ao passo que os seminários se destinavam à formação de futuros sacerdotes membros da Companhia. Considera que a expulsão dos jesuítas provocou o desmantelamento do processo educativo, contudo " $O$ objetivo do ensino continuou a ser a formação religiosa-humanista, seguindo os métodos utilizados pelos mestres-jesuítas" (GILES, 1987, p. 286).

Em História geral da pedagogia o tomo II traz um apêndice sobre o Brasil elaborado por Célio de Cunha, com 12 páginas dedicadas ao período colonial, enfatizando que os jesuítas, por 210 anos (1549-1759), "foram os únicos responsáveis pela nossa educação" (LARROYO, 1974, p. 883).

Entre os jesuítas fundadores que construíram a base da educação brasileira, destaca os padres Nóbrega, Aspilcueta Navarro, Anchieta e também Luís Figueira, autor da Arte de gramática latina da língua brasileira (1621), com a qual "muito contribuiu para a evolução $e$ o aprimoramento do idioma". O referido padre "percorreu todo o Maranhão e o Amazonas, com sua obra catequética e pedagógica", sendo morto pelos indígenas na ilha de Marajó, em julho de 1643. Considera a obra jesuítica como "marco fundamental da nossa civilização". A grandiosidade do trabalho educacional dos jesuítas é medida pela evolução de uma modesta Escola de Letras fundada em 1549 na Bahia, para, além das escolas de primeiras letras, mais de uma dezena de colégios, quando de sua expulsão. Procura mostrar o "caos que dominou a educação no Brasil" após a expulsão dos jesuítas e faz uma rápida incursão sobre a reforma educacional empreendida pelo Marquês de Pombal, questionando: "se após haver tudo

Revista HISTEDBR On-line, Campinas, n.48, p.13-24 Dez.2012 - ISSN: 1676-2584 
destruído, como poderia edificar um novo mundo, sem recursos e com as mesmas estruturas antigas?" (LARROYO, 1974, p. 885-893).

Dos livros que mesclam a história da educação geral com a do Brasil, vejamos dois casos ilustrativos: História da educação e Filosofia e história da educação. No primeiro, sua autora, Maria Lúcia de Arruda Aranha, dedica ao período colonial alguns trechos da Unidade IV, subdividida em três partes. O Brasil aparece ao final de cada uma das divisões sempre com a preocupação por parte da autora em estabelecer as conexões entre o contexto local e o geral, por considerar que: "A história do Brasil Colônia não pode ser desvinculada da história européia, já que a colonização deve ser compreendida como a necessidade de expansão comercial da burguesia enriquecida com a Revolução Comercial" (ARANHA, 1989, p. 117).

Depois de expor sucintamente o contexto geral da época da chegada dos portugueses ao Brasil, considera que a educação não era meta prioritária para o colonizador, no entanto, as metrópoles européias enviavam religiosos para desenvolver trabalho missionário e pedagógico nas suas colônias, tendo como principal finalidade converter os índios e impedir que os colonos se desviassem da fé católica. Todavia, destaca outros fatores que ampliavam a importância da atividade missionária no processo de colonização.

[...] a questão não é simplesmente religiosa. Numa época de absolutismo, a Igreja, submetida ao poder real, é instrumento importante para ajudar na garantia da unidade política, através da uniformização da fé e da consciência. Portanto, a atividade missionária facilitará sobremaneira a dominação metropolitana. Nessas circunstâncias, a educação na colônia assume papel de agente colonizador. (ARANHA, 1989, p. 118).

Na segunda obra em destaque, os autores Claudino Piletti e Nelson Piletti afirmam, na apresentação, que o atributo do livro, particularizando-o dos demais que tratam do mesmo assunto, é a ênfase à educação brasileira, merecedora de cerca de um terço de suas páginas. Todavia, o período colonial aparece em um pequeno capítulo, o de número 17 (páginas 164 a 175) destacando tão somente a atuação dos jesuítas e enaltecendo suas ações. Vejamos alguns trechos da obra.

[...] com seu trabalho missionário, procurando salvar almas, abriam caminho à penetração dos colonizadores; com seu trabalho educativo, ao mesmo tempo em que ensinavam as primeiras letras e a Gramática latina, ensinavam a doutrina católica e os costumes europeus.

$[\ldots]$

Os jesuítas logo compreenderam que não seria possível converter os índios à fé católica sem, ao mesmo tempo, ensinar-lhes a leitura e a escrita. Por isso, ao lado da catequese, organizavam nas aldeias escolas de ler e escrever, nas quais também se transmitiam o idioma e os costumes de Portugal.

$[\ldots]$

Os jesuítas responsabilizaram-se pela educação dos filhos dos senhores de engenho, dos colonos, dos índios e dos escravos. A todos procuravam transformar em filhos da Companhia de Jesus e da Igreja, exercendo grande influência em todas as camadas da população. (PILETTI e PILETTI, 1986, p. 166-167).

Revista HISTEDBR On-line, Campinas, n.48, p.13-24 Dez.2012 - ISSN: 1676-2584 
Quanto a livros destinados mais especificamente a educação no Brasil, vejamos algumas considerações a respeito de: História da educação no Brasil, de Otaíza de Oliveira Romanelli, História da educação brasileira: a organização escolar, de Maria Luíza Santos Ribeiro e História da educação: a escola no Brasil, produção conjunta de Maria Elizabete Xavier, Maria Luisa Ribeiro e Olinda Maria Noronha.

O primeiro, embora dedicado ao período 1930-1973, traz, no capítulo 2, uma espécie de retrospectiva, na qual apresenta em 7 páginas o período colonial, chamando a atenção para a importação "de formas de pensamento e idéias dominantes na cultura medieval européia[...] através da obra dos jesuítas", favorecida pela família patriarcal e pela classe dominante, desejosa de hábitos aristocráticos de vida. Mas era apenas "a um limitado grupo de pessoas pertencentes à classe dominante que estava destinada a educação escolarizada" (ROMANELLI, 1980, p. 33). Aos demais, a ação educativa se dava através da catequese.

[...] A catequese assegurou a conversão da população indígena e foi levada a cabo mediante criação de escolas elementares para os "curumins" e de núcleos missionários no interior das nações indígenas. A educação que se dava aos curumins estendia-se aos filhos dos colonos, o que garantia a evangelização destes [...]

Assim, os padres acabaram ministrando, em princípio, educação elementar para a população índia e branca (salvo as mulheres), educação média para os homens da classe dominante, parte da qual continuou nos colégios preparando-se para o ingresso na classe sacerdotal, e educação superior religiosa só para esta última. A parte da população escolar que não seguia a carreira eclesiástica encaminhava-se para a Europa, a fim de completar os estudos, principalmente na Universidade de Coimbra, de onde deviam voltar os letrados.

A obra de catequese, que, em princípio, constituía o objetivo principal da presença da Companhia de Jesus no Brasil, acabou gradativamente cedendo lugar, em importância, à educação da elite. E foi com essa característica que ela se firmou durante o período em que estiveram presentes no Brasil os seus membros e também com essa mesma característica que ela sobreviveu à própria expulsão dos Jesuítas, ocorrida no século XVIII. Dela estava excluído o povo e foi graças a ela que o Brasil se "tornou, por muito tempo, um país da Europa", com os olhos voltados para fora, impregnado de uma cultura intelectual transplantada, alienada e alienante. Foi ela, a educação dada pelos jesuítas, transformada em educação de classe, com as características que tão bem distinguiam a aristocracia rural brasileira, que atravessou todo o período colonial e imperial e atingiu o período republicano, sem ter sofrido, em suas bases, qualquer modificação estrutural [...] (Idem, p. $35)$.

O segundo livro em apreço, História da educação brasileira: a organização escolar, foi publicado pela primeira vez em 1978 e inovou a forma de abordagem na nossa historiografia educacional, fugindo da tradicional divisão política e procurando tratar o tema de forma global, vinculado ao desenvolvimento da base material da sociedade brasileira. Trata-se de um verdadeiro best-seller da área. A autora, consoante os critérios que adotou para efeitos de periodização, destaca "[...] os instantes de relativa estabilidade dos diferentes modelos - político, econômico, social - dos instantes de crise mais intensa e que causaram as 
substituições dos modelos referidos." (RIBEIRO, 1993, p. 16). Como marco inicial da educação escolar brasileira, aponta a chegada dos jesuítas chefiados pelo padre Manoel da Nóbrega e considera que, entre os anos de 1549 e 1808, a organização escolar deu-se no contexto da consolidação do modelo agrário-exportador dependente.

O terceiro livro da série indicada divide-se em duas partes, sendo pertinente para esta análise apenas a primeira, elaborada por Maria Elizabete Xavier e denominada "A Sociedade Agroexportadora e a Constituição do Ensino de Elite (1549-1920)" que coloca como centro de atenção o processo de elitização da educação escolar no Brasil. Conforme a análise desenvolvida pela autora aquele período

[...] constitui o momento no qual a organização social brasileira se constrói sobre uma base econômica de exploração agroexportadora, utilizando-se de relações de trabalho pré-capitalistas, como a escravidão e a semi-servidão. É quando, em plena Modernidade, a produção de bens se organiza em bases técnicas rudimentares, de forma extensiva e predatória. (XAVIER, 1994, p. 26).

Por conseguinte, no âmbito educacional, foi constituído "[...] de forma sofisticada e explicitamente seletiva, o ensino Colonial e, posteriormente, os ensinos Nacional, Imperial e Republicano" (XAVIER, 1994, p. 26-27)

Ao se perguntar sobre o tipo de cultura que poderia se desenvolver nas condições materiais daquela época, conclui:

[...] uma que fosse marcada pelo autoritarismo típico da religião institucionalizada, pelo elitismo de uma estrutura social brutalmente dividida em extremos intocáveis e pelo caráter contemplativo adequado às existências ociosas, dos que viviam da produção primária de produtores compulsórios. (Idem, p. 33).

Mostra que os Colégios Jesuíticos foram os centros por excelência de formação das elites e das lideranças da sociedade colonial. Mas que não se tratava de um ensino alienado, dogmático e acrítico e sim de possibilitar, também na colônia, o modelo cultural existente na metrópole, consoante com as diferenças em razão da posição dos indivíduos na sociedade (XAVIER, 1994, p. 46-47).

Com um título sugestivo: Grandezas e misérias do ensino no Brasil, o livro de Maria José Garcia Werebe, lançado em 1963 e relançado em 1994, com vários acréscimos, também é uma obra que, a exemplo das anteriormente citadas, apresenta uma visão panorâmica da nossa história educacional. O capítulo I trata do período colonial abordando a atividade dos jesuítas, sua expulsão e as conseqüênciasdaí decorrentes e os acontecimentos relativos à vinda da família real portuguesa para o Brasil. Também adota como marco inicial da escolarização no Brasil a chegada dos quatro padres e dois irmãos jesuítas chefiados por Manoel da Nóbrega ${ }^{2}$, fazendo a seguinte análise:

E assim se iniciou a educação no Brasil, respondendo aos interesses políticos da Metrópole e aos objetivos religiosos e políticos da Companhia de Jesus. A Companhia se propunha, desde suas origens, a combater o protestantismo, ocupando uma posição proeminente nas lutas que se 
travavam na Europa contra a Reforma e o "modernismo" que esta representava. À Metrópole interessava a catequização dos indígenas que, assim, se tornariam mais submissos e poderiam mais facilmente aceitar o trabalho que deles exigiam os colonizadores. (WEREBE, 1994, p. 21).

Em Instrução pública no Brasil (1500-1889): história e legislação, publicada originalmente em francês, no ano de 1889, o tradutor da edição consultada, AntonioChizzotti, em nota de apresentação, explica que o título e o texto conservam o termo instrução pública para designar a educação, pois assim era empregado até por volta dos anos 30 do século XX. $\mathrm{O}$ autor, Pires de Almeida, convicto da possibilidade da transformação da sociedade pela difusão da instrução, aponta a importância da escola para o progresso intelectual e moral da nação. Dedicado ao conde D'Eu, o livro visava mostrar o avanço educacional no país e o empenho do Império brasileiro nessa tarefa, inclusive comparando com outros Estados, razão pela qual foi escrito em francês, língua já universalmente conhecida. Para mostrar que os eventuais insucessos deviam-se à fase precedente, assim se expressa o autor:

O governo colonial do Brasil, ao contrário dos governos coloniais de outros povos, como o da Espanha, sempre foi hostil ao desenvolvimento da instrução pública e - salvo raras exceções - sempre reprimiu a expansão do espírito nacional. Desde os fins do século XVIII, vê-se despontar, nas instruções do governo metropolitano, o temor da futura independência da colônia. (ALMEIDA, 2000, p. 37).

Como os jesuítas foram os principais protagonistas da educação no Brasil colonial, a leitura da monumental obra escrita pelo padreSerafim Leite ainda é um dos melhores referenciais para quem busca informações detalhadas e abrangentes acerca das atividades por eles desenvolvidas no Brasil. A História da Companhia de Jesus no Brasil é dividida em dez tomos, dos quais o último corresponde ao índice dos anteriores. O tomo III trata da catequese, aldeamentos e colonização nas províncias do Ceará, Maranhão, Pará e Amazonas. Composto por 4 livros, cada um refere-se a uma província.

$\mathrm{O}$ tomo IV retrata diferentes aspectos referentes à colonização e às Missões do Maranhão e Grão-Pará. Destaca a atuação do Padre Antônio Vieira, na defesa pela liberdade dos índios e os embates com os colonos do Maranhão e Grão-Pará. Aborda ainda os aldeamentos e a catequese dos índios, fornecendo um panorama geral acerca da administração, dos serviços dos padres, governo das aldeias, e da decisão do Estado português de dividir as aldeias da Amazônia. Mostra as dificuldades enfrentadas pelos padres e as formas encontradas para a subsistência nas Missões do Norte.

Este tomo é bem amplo, sendo descritivo e detalhado, fornecendo um panorama geral das Missões do Maranhão e Grão-Pará, desde a chegada dos jesuítas até sua expulsão. É importante ressaltar que Serafim Leite pouco menciona sobre a resistência indígena à catequese, passando a idéia de que, em relação aos nativos, os jesuítas não tiveram maiores problemas. Provavelmente, por ser ele próprio um integrante daquela Ordem, mesmo que de uma outra época, não tenha tido interesse de explorar aquela questão em profundidade. Por outro lado, são bastante detalhados os conflitos políticos com os demais colonos.

Serafim Leite tem sido fonte de consulta obrigatória para os estudiosos da ação educacional dos jesuítas. Concordando-se com ou discordando-se de seus argumentos, é inegável que prestou um grande serviço à história da educação brasileira, retratando a face 
pedagógica e missionária da Ordem dos jesuítas. Luis Alves de Mattos, Leonel Franca, Baeta Neves, entre outros, também seguiram esta mesma tendência, mostrando o que foi e como foi a obra educacional dos primeiros educadores do Brasil.

\section{Novas contribuições a história da educação na Amazônia}

No tocante aos trabalhos mais específicos resultantes de dissertações de mestrado ou teses de doutoramento, sem detrimento de outros, fazem-se dois destaques, um em cada gênero mencionado: Colonização e catequese ${ }^{3}$, de José Maria Paiva, e Origens da educação estatal na América Portuguesa, de Alberto Damasceno. ${ }^{4}$

Penetrando no complexo das relações que entrelaçavam Fé e Império no contexto quinhentista, Paiva demonstra que a catequização cumpriu um papel colonial, não como aliada externa, mas como uma força realmente integrada a todo o processo. Na introdução, faz o seguinte esclarecimento:

Entendemos por catequese toda ação pastoral da Igreja: a doutrinação propriamente dita, a pastoral litúrgico-devocional, o comportamento das pessoas e das instituições eclesiásticas. Trata-se, na verdade, da catequese tal qual se realizou efetivamente e não de uma catequese teórica, universal, uniformemente transmitida para todos os povos, indiferentemente. (PAIVA, 1982, p. 13).

O conhecimento do autor citado, em matéria religiosa, assim como a clareza na exposição fazem com que a obra seja acessível ao entendimento e descortine o mundo que girava em torno do orbischistianus ${ }^{5}$.

Damasceno, por sua vez, dedicou-se a sistematizar e analisar idéias e dados sobre as origens da educação pública estatal na América portuguesa, partindo da compreensão de que no governo de Francisco Xavier de Mendonça Furtado, no Estado do Grão-Pará e Maranhão entre os anos de 1751 e 1759, foi dado início a um amplo processo de transformações que culminaria, dentre outros acontecimentos, com o surgimento - pela primeira vez na América portuguesa - de escolas estatais que viriam a substituir o sistema jesuítico de educação elementar, antes mesmo da reforma do ensino de Carvalho e Melo deflagrada em 1759 em Lisboa. O instrumento legal utilizado para que isso acontecesse foi o "Diretório" de 1757, objeto central da tese.

Ainda com relação à bibliografia que utilizei para compreender o tema, destaco a tese de Alex Fiuza de Mello, defendida na Unicamp e intitulada Marx e a globalização, assim como uma obra mais recente, sobre a qual explica que realizou

[...] uma releitura cuidadosa de toda a obra de Marx, desde os chamados textos de juventude até $O$ Capital, e que implicou num resgate e sistematização de toda uma linha de argumentação que, ainda que de forma esparsa, ali se encontra presente, e cujo enfoque revela particularmente instigante e merecedor de notoriedade. Para Marx - é preciso dar relevo! capitalismo é também sinônimo de civilização: eis o real sinônimo heurístico de suas formulações (e de implicações teóricas nada desprezíveis)! (MELLO, 2001, p. 13).

Revista HISTEDBR On-line, Campinas, n.48, p.13-24 Dez.2012 - ISSN: 1676-2584 
Embora tenha feito menção a alguns autores, quero deixar registrado que todas as leituras empreendidas (cuja listagem completa consta no final do texto) contribuíram igualmente para a elucidação do tema. Ainda com relação à bibliografia utilizada nesta tese, ressalto que optei por manter o padrão ortográfico presente nas obras consultadas, que embora difira do atual, creio que não compromete a sua leitura e o seu entendimento.

Com exceção dos trabalhos mais específicos, ainda há poucos estudos acerca dos acontecimentos educacionais relativos ao Grão-Pará. Geralmente, o Brasil é tratado de maneira uniforme. O longo período de colonização que se estende da chegada dos portugueses até a emancipação política é analisado, do ponto de vista da história da educação, basicamente em três momentos: o do predomínio quase absoluto dos jesuítas (1549-1759), o das reformas pombalinas (após a expulsão dos jesuítas) e o joanino (1808-1822). Considerando essa realidade, procurei incorporar as contribuições dos diferentes autores e, ao mesmo tempo, investigar as especificidades que marcaram os primórdios da educação no Grão-Pará.

$\mathrm{Na}$ tese de doutorado que defendi junto ao programa de pós graduação da Unicamp, demonstrei, com o apoio de vários autores que se dedicaram a compreender os fatores contextuais dos chamados Grandes Descobrimentos, como o expansionismo português aglutinou interesses religiosos, políticos e econômicos. Movendo-se pela necessidade de obtenção e acumulação de riquezas, a burguesia mercantil estabelecida no "velho mundo" alastrou-se nas diversas áreas colonizadas, articulando-se ao processo mais amplo de desenvolvimento do capitalismo.

Para conseguir seus propósitos, os colonizadores usaram de diferentes meios, com o suporte de duas importantes instituições: o Estado e a Igreja. Os religiosos tinham como missão converter os gentios, assim como manter os colonos na "santa fé católica", da qual o rei apresentava-se como principal interessado na sua propagação e defesa. Desta forma, colonização e catequese integraram-se ao movimento de inserção de territórios e de pessoas no chamado mundo ocidental e cristão.

Em terras brasileiras, os portugueses encontraram comunidades indígenas nas quais prevaleciam relações igualitárias e de cooperação, sem a ocorrência do comércio. Em princípio, os índios serviram de admiração, como relatam diversas correspondências dos primeiros cronistas. Depois foram utilizados como mão-de-obra ou simplesmente dizimados.

No lento e longo processo de "adaptação" ao trabalho destinado à produção de excedentes para o comércio, os índios foram submetidos a uma intensa aculturação. Distanciando-se das velhas formas de aprendizagem, das crenças, e dos costumes legados pelos seus antepassados, ficaram vulneráveis às novas formas de interpretação do mundo apresentadas pelos colonizadores. Assim, principalmente as novas gerações foram sendo "educadas" para que se afastassem dos comportamentos "selvagens" e incorporassem os padrões "civilizados" definidos pelo colonizador europeu.

A atividade educacional dos primeiros educadores do Brasil, os jesuítas, assim como dos demais integrantes das diversas Ordens religiosas que se estabeleceram na colônia, reforçava a dominação portuguesa sobre a população nativa. Cuidando da conversão dos índios à religião cristã e introjetando novos costumes através dos aldeamentos, os missionários levavam a cabo o trabalho de catequese, e também desenvolviam a instrução formal. Assim, as primeiras experiências pedagógicas nasceram visando catequizar os índios e transformá-los em seres "civilizados".

Revista HISTEDBR On-line, Campinas, n.48, p.13-24 Dez.2012 - ISSN: 1676-2584 


\section{Considerações finais: Convite a continuidade.}

A trajetória histórica da educação na Amazônia colonial, sob a ótica dos autores analisados ao longo deste texto, de um modo geral, assemelhou-se ao que ocorreu em outras regiões da principal colônia portuguesa na América. As Ordens religiosas foram seus primeiros e principais protagonistas, auxiliando a Coroa no processo de dominação cultural da população nativa. No período pré-pombalino - 1616 a 1750 - a escolarização ficou totalmente nas mãos dos religiosos. Na fase posterior, sem uma efetiva atuação do Estado, e com a expulsão dos jesuítas, agravaram-se os problemas que já eram intensos. Escolarização restrita a privilegiados, em um contexto social onde poucos a ela podiam ter acesso. Aos demais, a absoluta maioria, restava a catequização, embora nesta também estivesse presente o sentido educativo.

A colonização atendeu aos interesses mercantis presentes no expansionismo português, através da associação da Igreja e do Estado, e propiciou as condições para o desenvolvimento do capitalismo tanto na Europa quanto no Brasil. Naquele contexto, catequese e educação foram faces de uma mesma moeda e serviram para implantar, no "novo mundo", os padrões de civilidade que interessavam aos novos tempos, caracterizados pela formação de uma imensa massa de trabalhadores desprovidos dos meios de produção e, por isso mesmo, obrigados a venderem-se como força de trabalho.

Conforme se apontou na introdução, um dos objetivos era o de contribuir para a compreensão histórica da educação em âmbito regional, a partir da elucidação dos fatores interligados aos primórdios do seu desenvolvimento, sempre considerando que o singular se articula com o geral, pois ambos são expressões de um dado momento do modo de produção que preside as relações humanas.

Por fim, reitera-se o fato de que, assim como este trabalho foi inspirado em leituras de autores que se dedicam ao estudo e ao ensino da história da educação, espera-se que ele também sirva como ponto de partida para outras investigações e novos esclarecimentos sobre a história da educação na Amazônia.

\section{Referências}

ALMEIDA, José Ricardo Pires de. História da instrução pública no Brasil (1500-1889): história e legislação. Tradução AntonioChizzotti. São Paulo: EDUC; Brasília: INEP/MEC, 2000 .

ARANHA, Maria Lúcia de Arruda. História da educação. 2 ed. São Paulo: Moderna, 1989.

BAENA, Antonio Ladislau Monteiro. Compêndio das eras da Província do Pará. Belém: Universidade Federal do Pará, 1969. (Coleção Amazônia, Série José Veríssimo).

BETTENDORFF, Pe. João Felipe. Crônica da missão dos padres da Companhia de Jesus no Estado do Maranhão. 2. ed. Belém: Fundação Cultural do Pará Tancredo Neves/Secretaria de Estado da Cultura, 1990.

COLARES, Anselmo Alencar. Colonização, catequese e educação no Grão-Pará. Editora da Ulbra, 2005.

Revista HISTEDBR On-line, Campinas, n.48, p.13-24 Dez.2012 - ISSN: 1676-2584 
DAMASCENO, Alberto. Origens da educação estatal na América portuguesa. Tese de Doutorado. PUC-SP, São Paulo, 1998.

FERREIRA, Aurélio Buarque de Holanda. Novo dicionário da língua portuguesa. 2 ed. rev. e aum. Rio de Janeiro: Nova Fronteira, 1986.

GILES, Thomas Ransom. História da educação. São Paulo: EPU, 1987.

LARROYO, Francisco. História da educação e da pedagogia. São Paulo: Mestre Jou, 1974. $2 \mathrm{~V}$.

MELLO, Alex Fiúza de .Modo de produção mundial e processo civilizatório: os horizontes históricos do capitalismo em Marx. Belém: Paka-Tatu, 2001.

PAIVA, José Maria de. Colonização e catequese. São Paulo: Cortez, 1982.

PILETTI, Nelson; PILETTI, Claudino. Filosofia e história da educação. 4 ed. São Paulo: Ática, 1986.

PRADO Jr. Formação do Brasil contemporâneo: colônia. São Paulo: Brasiliense/ Publifolha, 2000. (Grandes nomes do pensamento brasileiro).

RIBEIRO, Maria Luisa Santos. História da educação brasileira: a organização escolar. São Paulo: Cortez/Autores Associados, 1993.

SANTOS, AileneContreiras dos. Estudo documental da atuação jesuítica e franciscana na educação do Brasil-Colônia (1500-1808). Tese de Livre Docência. Faculdade de Educação, UFRJ, Rio de Janeiro, 1974.

SAVIANI, Dermeval. Educação e colonização: as idéias pedagógicas no Brasil nos séculos XVI, XVII e XVIII. Campinas: [s.n.], 1997. (mimeo).

VARNHAGEN, Francisco Adolfo de. História geral do Brasil antes de sua separação e Independência de Portugal. Belo Horizonte: EDUSP, 1981.

VIEIRA, Pe. Antonio. Escritos instrumentais sobre os índios. São Paulo: EDUC, 1992.

WEREBE, M. J. Grandezas e misérias do ensino no Brasil: 30 anos depois. São Paulo: Ática, 1994.

XAVIER, M. E. S. P. A sociedade agroexportadora e a constituição do ensino de elite (15491920). In: XAVIER, M. E. S. P.; RIBEIRO, M. L. S.; NORONHA, O. M. História da educação: a escola no Brasil. São Paulo: FTD, 1994.

Revista HISTEDBR On-line, Campinas, n.48, p.13-24 Dez.2012 - ISSN: 1676-2584 
Notas:

${ }^{1}$ O compêndio "livro de texto para escolas" é também sinônimo de manual: "livro que contém noções essenciais acerca de uma ciência, de uma técnica etc.". Abordam, em forma de síntese, inúmeros temas, ao contrário da monografia, que corresponde a "dissertação ou estudo minucioso que se propõe esgotar determinado tema relativamente restrito" (FERREIRA, 1986, p. 439, 1084 e 1154).

${ }^{2}$ Este entendimento é praticamente unânime. Na bibliografia que consultei, apenas deparei-me com uma exceção. Ailene C. dos Santos, em Tese de Livre Docência apresentada a UFRJ, tendo como título Estudo documental da atuação jesuítica e franciscana na educação do Brasil-Colônia (1500-1808), nas conclusões, observa que houve uma série de diferenciações entre as duas Ordens, responsáveis pelo maior sucesso dos jesuítas no campo educacional, mas foram os franciscanos, na sua interpretação, os pioneiros da educação no Brasil. "Embora de início a obra franciscana tenha se limitado à pregação e à catequese, não se pode esquecer que já em 1538, portanto onze anos antes da chegada dos jesuítas, esses missionários mantinham em Biaça um núcleo educacional organizado, onde desenvolviam ao lado da educação religiosa a educação moral e profissional". Todavia, reconhece que a atuação dos franciscanos foi bastante irregular, e sem a organização e a rigorosidade funcional da Companhia de Jesus, além de que, não contaram com as mesmas regalias que os jesuítas, vindos ao Brasil "como legítimos representantes do governo português, com a incumbência explícita de catequizar o gentio e auxiliar a colonização". Assim, ressalta, "embora tenha cabido aos franciscanos iniciar a história da educação brasileira, coube aos jesuitas der-lhes estrutura, organização e continuidade". (SANTOS, 1974, p. 264-267).

${ }^{3}$ O papel da catequese dos índios no processo de colonização: 1549-1600 é o título original da dissertação de mestrado defendida na Unicamp em 1978, sob a orientação do Prof. Dr. Casemiro dos Reis Filho.

${ }^{4}$ Tese defendida em março de 1998, na PUC-SP, sob a orientação do Prof. Dr. AntonioChizzotti.

5 “[...] uma imagem cristã medieval do mundo. Fundou-se na crença de que o mundo é de Deus, cujo representante na terra é a Igreja Católica. Este Deus, por ser verdadeiro, exigia que todos o reconhecessem e lhe prestassem culto [...]" (PAIVA, 1982, p. 21-22).

Recebido em novembro/2012

Aprovado em dezembro/2012

Revista HISTEDBR On-line, Campinas, n.48, p.13-24 Dez.2012 - ISSN: 1676-2584 